A pesquisa e a prática de Maria Cristina Kupfer no Lugar de Vida questionam as noções geralmente admitidas de estrutura, de sujeito, de autismo e de psicose. $O$ texto que segue tenta discernir melhor a psicose do autismo, que, se aceitos nesta nova formulação, deveriam gerar uma clínica diferente para as crianças.

Psicose; autismo; estruturas; sujeito

\section{RECONSIDER THE} PSYCHOSIS AND AUTISM CONCEPTS

The research and practice of Maria Cristina Kupfer on Lugar de Vida question the generally accepted notions of structure, subject, autism and psychosis. The following text aims to bighlight the differences between psychosis and autism. If these differences are acknowledged in this form, children should benefit from a different kind of treatment. Psychosis; autism; structures; subject

\section{REPENSAR OS \\ CONCEITOS DE \\ PSICOSE E DE AUTISMO $^{1}$}

Philippe Willemart

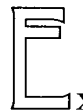

xperiência bem-sucedida no âmbito da Universidade de São Paulo, o movimento Lugar de Vida sublinha a dimensão social não somente da universidade, mas da psicanálise, mostrando como é possível entrelaçar pesquisa, ensino e extensão. Outras instituições tratam da infância com problemas, Bonneuil, Le Courtil e o CPPL, mas Maria Cristina Machado Kupfer e sua equipe construíram o Lugar de Vida diferente e original que merece nossa admiração pela organização, a revista Estilos da Clínica, a reflexão, os avanços teóricos e a repercussão na comunidade. O Lugar de Vida é uma resposta a Settembrini, personagem de Thomas Mann que negava a psicanálise porque "prejudica as raízes da vida e estorva a ação”.

A tese de livre-docência da fundadora resume bastante a problemática psicanálise-educação, responde em parte a questões-chave que muitos educadores e professores apresentam, testemunha uma iniciativa pessoal e uma experiência de equipe da qual poucos podem se vangloriar, mas levanta algumas perguntas teóricas nas quais vou me deter.

Coordenador do Núcleo de Apoio à Pesquisa em Crítica Genética. Diretor do Laboratório do Manuscrito Literário, Universidade de São Paulo. 
Se admitirmos a tese de Catherine Millot de que o autismo e a psicose não permitem a instalação da criança "na ordem simbólica pela travessia do Édipo e da castração", haveria somente soluções paliativas no tratamento. Socializar melhor a criança ou inseri-la um pouco mais no registro do Simbólico seriam os objetivos máximos a serem atingidos, sabendo todavia que a falta de precisão dos advérbios "melhor" e "mais" reflete a ausência de parâmetros que determinariam uma verdadeira inserção no Simbólico. Conseguir desencadear a formação do sujeito seria impossível (Millot, 1979).

\section{A CRIANÇA AUTISTA}

No entanto, temos a experiência contrária da antropóloga em Marte, como ela se denominava, a dra. Temple, bióloga e pesquisadora-professora na Universidade do Colorado (Sacks, $1995^{\circ}$, p.253) que parece ter atravessado o Édipo e a castração e pôde deixar correr seu desejo. Diferentemente, ela nos faz entender o quanto um autista não é psicótico e precisa de outro tratamento. Sacks, que relata o caso, não é psicanalista e acredita na causa orgânica do autismo, mas suas descrições são bastante plausiveis e me levam a perguntar se podemos confundir as duas categorias na abordagem.

Na revista Estilos da Clinica, dois artigos aludem ao autismo. Um de Jerusalinsky sobre a psicose, mostrando em três linhas que o autismo não é uma variedade dentro das psicoses, mas uma outra forma de organização psíquica (1996, p.146), e um de Atem (1997, p.83), mais elaborado, que conta uma experiência consistente.

Levando em conta a distinção de Jerusalinsky pondo os autistas do lado da falha materna e os psicóticos do lado da falha paterna, pergunto se não haveria outras contribuições válidas que pudessem auxiliar a terapeuta de crianças classificadas como tais.

Segundo Frances Tustin, "a criança tenta salvar o existente apegando-se a um mini-universo de sensações no qual o tocar é o mais importante ... o mundo autístico é sem espessura, bidimensional, arquipélago de superfícies planas cercadas de beiras que pertencem tanto ao mundo exterior quanto o corpo do sujeito. ... Assim, essas 'sensações-formas', provocadas por percussão, esfregamento, afloramento, balanceamento, [que] geram fluxos de sensações apaziguadoras e tranqüilizadoras" (Tustin, 1993). Lou Muniz Atem constata os mesmos fenômenos no artigo citado.

Num ensaio de 1994 sobre a Busca do tempoperdido de Proust, Julia Kristeva, que, em 1983, já atendia algumas crianças de Bonneuil $^{2}$, retoma Tustin e define o sintoma do autista como uma impossibilidade de ter acesso à linguagem, embora tenha 
uma vida sensorial muitas vezes complexa. Lembrando a caverna de Platão, ela imagina no autista "a existência de uma caverna sensorial desprovida de símbolos (ou de sombras no sentido platônico) na qual pode encontrar representações de coisas ... não traduzidas necessariamente por representações de palavras" (1994, p.289).

Em seguida, Kristeva lança uma hipótese ousada e afirma que "Proust consegue lá onde o autista fracassa". Ela cita um trecho de Sodoma e Gomorra (Proust, 1994, p.317) no qual o narrador proustiano, por meio do herói Marcel dormindo profundamente, descreve um segundo apartamento ou a caverna sensorial, sem réplica de si, sem duplo e sem alter ego, fora do tempo, com traços arcaicos de não diferenciação sexual e de sensação imemorial, caverna que poderia ajudar os terapeutas e os psicanalistas a entender um pouco mais o que vivem os autistas. O início do romance evoca uma atmosfera parecida, quando o herói assume identidades estranhas, dilacerado entre o sono e o acordar: "Durante o sono, não havia cessado de refletir sobre o que acabara de ler, mas essas reflexões tinham assumido uma feição um tanto particular; parecia-me que eu era o assunto de que tratava o livro: uma igreja, um quarteto, a rivalidade entre Francisco I e Carlos V" (Proust, s./d., p.9).

As interpretações de Proust, Kristeva, Tustin e Atem não contradizem aparentemente o relato de Sacks sobre Temple, e, se concordamos, esse é mais um exemplo da riqueza da literatura que, na esteira de Freud e Lacan, incentiva o psicanalista a conhecê-la para entender melhor o ser humano.

\section{A CRIANÇA PSICÓTICA}

Maria Cristina Kupfer caracteriza a criança dita psicótica da seguinte maneira: "O que falta é a falta ..., a estrutura que as organiza pode ser comparada à de uma frase melódica sem um repouso na tônica, o que equivale a uma frase sem ponto final ... falta-lhe esse momento de interrupção e o sentido que pode advir?" (Kupfer, 1999, p.107).

No seminário sobre as psicoses, Lacan precisa que no psicótico "a linguagem fala sozinha, a voz alta, sem sujeito. Ele é habitado, possuído pela linguagem" (1955-56, p.4). E prossegue no Seminário $V$ : "A psicose é o último recurso, pelo menos o mecanismo essencial, da redução do grande Outro, do outro como sede (assento) da palavra ao outro imaginário. É uma substituição do simbólico pelo imaginário" (1998. p.12). Isto é, enquanto o neurótico circula entre os três registros, o psicótico esvazia ou diminui o Simbólico sob a pressão do Imaginário e circula apenas do Real ao Imaginário. "O significante um" não passa embaixo da barra, o que não permite a eclosão do sentido. 
Comparando oautista eopsicótico, diria que o primeiro ignora o Simbólico, e o segundo o substitui. O tratamento deveria inserir o autista no Simbólico nas suas várias dimensões, e no psicótico descolar o Simbólico do Imaginário. Isto é, as crianças têm em comum a falta de um sujeito deslizante de significante em significante, o que leva a terapia a ter o mesmo objetivo: restituir ou fazer emergir esse sujeito, embora parte de âncoras diferentes.

A definição da libido por Lacan como o ponto de interseção entre a realidade sexual e o campo do desenvolvimento do inconsciente (1995, p.148) ajuda a entender a diferença entre a psicose e o autismo.

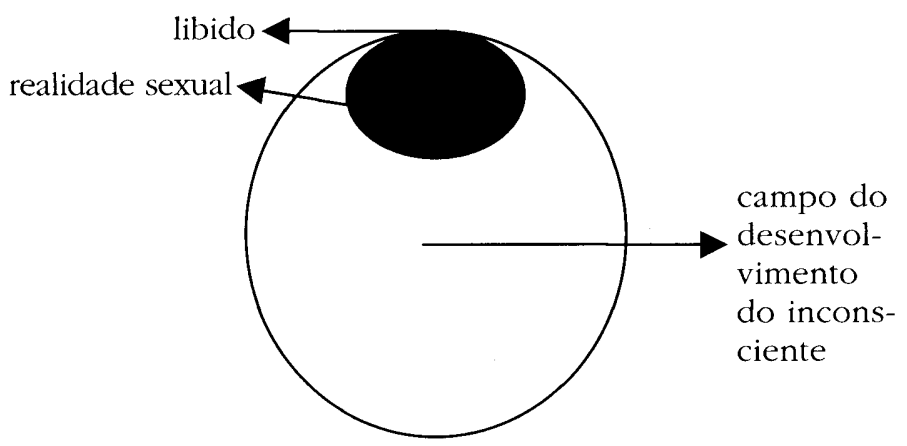

Os dois campos do desenho formam um oito, ou, melhor ainda, uma Fita de Moebius. Se a libido ou o desejo ou a faltafalha não funciona, isto é, se não há conexão ou passagem de uma para outra, o autista fica acantonado no campo das pulsões, e o psicótico no campo do grande Outro. É como se a Fita de Moebius fosse uma fita normal, sem torção, sem possibilidade de encontro entre os dois lados, ou como se os dois rírculos do oito não se tocassem.

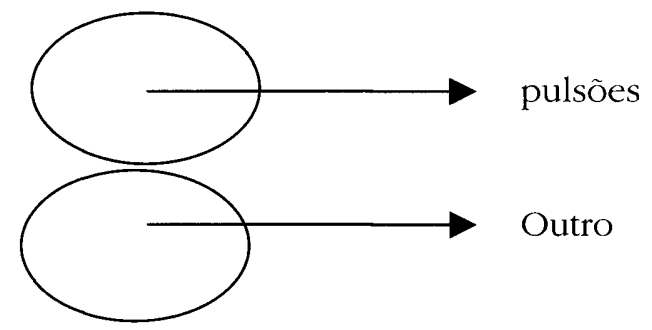

No comentário do Bloco mágico, Freud sublinhava que a escanção do tempo opera quando as camadas são reunidas pelo lápis que escreve, caso contrário, a psique fica no tempo eterno do inconsciente. O lápis que pressiona as camadas poderia ser 
comparado facilmente à libido que provoca a conexão entre os dois campos, o das pulsões e o da linguagem. A criança psicótica, tanto quanto o autista, dificilmente conecta os dois campos.

A partir dessa descrição e dessa falha comum para as duas categorias, duas disfunções poderiam ocorrer; $\mathrm{O}$ condicional sublinha que a distinção é raramente observada em "estado puro" no Lugar de Vida, como ressalta Kupfer.

Ou a criança viveria totalmente sexuada, isto é, fechada no campo das sensações e das pulsões, ou ficaria no campo do grande Outro.

1. No primeiro caso, a criança autista se movimentaria inteiramente no campo da realidade sexual sem poder dizê-lo em palavras e, portanto, ignoraria o princípio de realidade que dessexualiza ou deserotiza o real empíico. Observo, entretanto, que, conforme escreve Atem, a criança, mesmo assim, tem falha no circuito pulsional e não consegue relacionar a sensação e a pulsão que a projetaria no grande Outro. Durante sua formação, o herói da Busca do tempo perdido caminha sempre da sensação às lembranças, às idéias, à inteligência como se partisse de uma situação autista, o que me leva a perguntar por que Proust estava tão empenhado em valorizar a sensação e pôr a inteligência de lado. Ele já tinha afirmado em 1908: "Todo dia, ligo menos para a inteligência. Todo dia, me dou conta de que é somente fora dela que o escritor pode pegar algo de nossas impressões passadas, isto é, atingir algo dele mesmo e a única matéria da arte" (Proust, 1971, p.211). A origem da arte segundo Proust está nesse campo das sensações. Se Freud ouvia a histérica no final de século, Proust descrevia já o autista no começo do século XX, justificando a afirmação de Manoel Tosta Berlinck, que, na argüição de li- vre-docência de Kupfer, atribuía o autismo a todos os seres humanos.

Se a arte exige um certo autismo, não é porque o artista seja autista, mas no sentido de que ele deve voltar à caverna sensorial, tão próxima se não parte do registro do Real, para reencontrar a fonte da criação. O artista faz essa volta "imaginarizando" o Simbólico que o cerca, isto é, relativizando as estruturas de todo tipo nas quais ele está inserido (Willemart, 1995, p.121), contrariamente ao autista, que deveria simbolizar as sensações vividas intensamente.

2. Quanto à criança psicótica, ela viveria exclusivamente no campo do grande Outro, à mercê dele, sem poder barrá-lo, resistindo à vivência das pulsões oral, anal, escópica e do ouvir.

A radicalidade da distinção de dois campos ajuda talvez a entender como funcionaria o RSI da criança com problemas, mas será que ela vai ao encontro da criança real e das terapias aplicadas? Em tese, as terapias usadas para os autistas visariam a abrir o circuito da pulsão ao grande Outro ou à linguagem, enquanto outras terapias tenderiam a abrir o circuito para as pulsões nos psicóticos, mas o essencial consistiria em suscitar ou aumentar a conexão entre os dois campos introduzindo a criança no tempo calendário por todos os meios possíveis.

\section{AS ESTRUTURAS \\ E O SUJEITO}

Juranville enumerou quatro estruturas existenciais: a psicótica, a neurótica, a perversa e a sublimatória, às quais Jerusalinsky sugere acrescentar a estrutura autística.

O estruturalismo data dos anos 60 , e pergunto se ainda temos que pensar nessa perspectiva hoje. Eu estaria muito cauteloso nesse ponto e tentaria em 
primeiro lugar diminuir o impacto estruturalista que cercou o afloramento do pensamento lacaniano. Enveredando por aí, me dou conta de que, embora anule, se não relativize, minha argumentação anterior, vale a pena abrir outros caminhos de entendimento.

Dois argumentos nos levam a repensar a ligação íntima entre o estruturalismo e a teoria lacaniana. A experiência clínica, por um lado, e a descrição do universo segundo Ilya Prigogine, Prêmio Nobel de Química de 1977, por outro.

A partir da escuta analítica, Berlinck, como já foi lembrado, imputa o autismo a todos os seres humanos. Kupfer, em contato permanente com crianças psicóticas e autistas, define o inconsciente ou o conjunto dos três registros lacanianos (o RSI) como uma sintaxe das estruturas possiveis. Prigogine afirma que "nossas descrições do mundo organizam-se em volta dos temas de estabilidade e de instabilidade, e não mais da oposição entre acaso e necessidade" (Prigogine \& Stengers, 1986, p.14). Foi mostrado que a estabilidade pode gerar a instabilidade, como comprova, por exemplo, um estudo do sono profundo. As cinco variáveis independentes que conseguem mapear os bilhões de neurônios do cérebro geram, por sua complexidade, um comportamento altamente imprevisível ou instável ${ }^{3}$.

Nessa perspectiva, as estruturas da psicose, da perversão e da neurose fariam parte de zonas de estabilidade e explicariam grande parte da complexidade psíquica dos homens, mas as "exceções", aqueles que não se encaixam ou que vivem em zonas de instabilidade (e reparamos que a estrutura sublimatória é altamente instável), antecedem as estruturas que conhecemos ou anunciam outras zonas de estabilidade ainda desconhe- cidas, mas verificáveis nos casos tratados no Lugar de Vida.

Em outras palavras, temos duas descrições possíveis.

Ou todos os homens são psicóticos (tese de Bion), ou autistas (tese de Berlinck), e, segundo o tempo lógico de cada um, essas primeiras estruturas não mudam, ou se "dissiparam" para gerar as três estruturas clássicas ou aceder à quarta" .

Segunda descrição: todos os homens encaixam-se nas três estruturas, mas por um fenômeno ainda inexplicável, e que inclui a flecha do tempo, alguns "dissiparam" as estruturas originárias e criaram outras.

Nas duas descrições, a terapia consiste em provocar o tempo lógico das crianças para "forçá-las" a entrar numa zona de estabilidade, ou a terapeuta aceita que as crianças vivem no mundo delas. A terapeuta tenta conversar e estabelecer a comunicação com esse mundo diferente sem o espírito missionário da conquista, acreditando que háum sujeitosemanifestandosemormoldes dosneuróticos. O paradigma de Prigogine permite entender um fato relatado por Sacks. A família autista que ele visitou tinha na biblioteca uma grande maioria de livros de ficção científica, e seus heróis eram o Dr. Spock e seus sucessores, os andróides (Sacks, 1995, p.281), e não personagens de novelas ou de romances.

Quanto ao problema do surgimento do sujeito, ele não se põe mais, se concordamos com as duas descrições: o sujeito existe e vive, embora de modo diferente, nas estruturas estáveis ou instáveis, confirmando assim as indicações de Kupfer e as dúvidas de Berlinck quanto ao sujeito lacaniano.

Contar bistórias (Inafuku \& Teperman, 1996, p.78). Se a criança psicótica prefere "falar com os fantoches, ver desenhos animados e aprender com eles, do que falar com seus pais 
ou professores" (Kupfer, 1999, pp.115 e 116), não é porque há uma identificação maior ${ }^{5}$ com um certo desejo vivido pelos primeiros? O sujeito que vive nessa criança, ou seu RSI, pode pular entre os significantes Branca de Neve, os Sete Anões ou o Pequeno Polegar, cuja paixão é mais evidente, e não entre os significantes-pessoas que o cercam. As histórias lhes permitem reencontrar um mundo semelhante, mas funcionam como para qualquer neurótico: elas questionam seu lugar no mundo, transformam, prolongam e diversificam o percurso do sujeito, admitindo outros significantes. Parecidas com o sonho narrado, as histórias contadas ou encenadas no teatro ou no cinema trabalham o sujeito e o transformam sem ele saber.

Escrever, alfabetizando ou não, é uma outra atividade do Lugar de Vida que possibilita não o surgimento do sujeito, mas seu caminhar. Diferente das histórias, a escritura exige um querer dizer imediato do sujeito e uma inserção no circuito da linguagem. Escrever sugere uma composição entre o outro e o grande Outro, entre a vontade de um eu e palavras carregadas de histórias, entre uma desordem inicial e uma sintaxe obrigatória. Como diz Kupfer, "escrever é produzir um 'a mais', que é o fruto dos encontros sintáticos, das vírgulas, da posição das frases, de seu encadeamento" (Kupfer, 1999, p.128). Desse "a mais" decorre um estilo que revela um sujeito (Willemart, 1996, p.201), e às vezes um artista quando consegue distanciarse do passado, como salienta Mallarmé: "O verso, que, com vários vocábulos, refaz uma palavra total, nova, estranha à língua e como encantadora, termina este isolamento da palavra: negando, com um traço soberano, o acaso alojado nas palavras ..." (Mallarmé, 1954, p.368) 6 . 
Oateliê de artes deixa a criança mais livre, já que a única imposição virá do material escolhido (Pfüitzenreuter, 1994 e 1997), e não de uma história já estruturada com enredo e personagens, nem das letras do alfabeto, limitadas em sua combinação e em seu número. Como o artista pintando ou gravando responde a uma demanda da sociedadé e propõe freqüentemente sem saber seu desejo a ver, assim a criança, lutando contra e com as cores, a argila ou o papel, encontra na arte mais uma ocasião de romper a ordem gozosa mantenedora do sintoma (Kupfer, 1999, p.116), esboçando ou afirmando seu desejo.

Para terminar, pergunto se ficamos no estruturalismo, que, mesmocontando com a história, quer estruturar o não estruturado, ou admitimos as novas descrições do universo baseadas no paradigma estabilidade-instabilidade que aceitam a desordem, o barulho, o ruído, provocadores de instabilidade e de estruturas dissipativas? Embora a finalidade da terapia seria levar as crianças com problemas nas nossas zonas de estabilidade, aceitamos que elas vivem em zonas de estabilidade próprias e até de instabilidade?

Descrever o indescritivel ou o ininteligível dessas zonas de instabilidade não seria também uma das funçôes de Lugar de Vida?

\section{REFERENNCIAS \\ BIBLIOGRÁFICAS}

Atem, L. M. (1997). Possibilidades de intervenção com o autismo a partir da circulação pulsional: passagem de uma recusa ativa à passividade que permite a pulsionalidade. Estilos da Clínica: Revista sobre alnfância com Problemas, 3, 83-90.

Chiampi, I. (coord.) (1991). A modernidade na literatura francesa. In Fundadores da modernidade (A. Pinheiro, trad.). São Paulo, SP: Ática.

Freud, S. (1972). A criação literária e o devaneio. In Ediçãostandard brasileira das obras completas de Sigmund Freud (J. Salomão, trad.) (Vol. 9, p.149). Rio de Janeiro, RJ: Imago [originalmente publicado em 1908].

Inafuku, C. K. \& Teperman, D. W. (1996). Eva, Pandora e Curumim: a curiosidade e as histórias. Estilos da Clínica: RevistasobreaInfância com Problemas, 1 , 78-93

Jerusalinsky, A. (1996). Para uma clínica psicanalítica das psicoses. Estilos da Clinica: Revistasobrealnfância com Problemas, 1, 146-63

Kristeva, J. (1994). Le temps sensible (Proust et l'expérience littéraire). Paris: Gallimard.

Kupfer, C. (1999). Umaeducaçãopara osujeito. Desdobramentos da conexãopsicanáliseeducação. Tese de livre-docência defendida no IPUSP.

Lacan, J. (1955-6). Le séminaire. Livre III. Cap. XX (ed. mimeografada).

- (1995). Seminário 11. Rio de Janeiro, RJ: Zahar, 1985.

(1998). Le séminaire. Livre V. Les formations delinconscient. Paris: Seuil.

Mallarmé, S. (1954). Crise de vers. In Oeuures complètes. Paris: Gallimard.

Millot, C. (1979). Freud, antipedagogo. Rio de Janeiro, RJ: Zahar.

Pfützenreuter, E. do P. (1994). O desejo material. Dissertação inédita. Pontifícia Universidade Católica, São Paulo, SP.

(1997). Material digital: consideraçôessobreouso de meios digitais. Tese inédita. Pontifícia Universidade Católica. São Paulo, SP.

Prigogine, I. \& Stengers, I. (1986). La nouvelle alliance (métamorphose de la science). Paris: Gallimard.

Proust, M. (1971). Contre Sainte Beuve. Paris: La Pléiade, Gallimard. (1987). Combray. À la recherche du tempsperdu. I. Paris: Gallimard.

- (s./d.). Nocaminbo deSuann.Em 
busca dotempoperdido, Vol. I.(M. Quintana, trad.). São Paulo, SP: Globo, p.9. (1994). Sodomae Gomoma (Femando

Py, trad.). Rio de Janeiro, RJ: Ediouro.

Sacks, O. (1995). Um antropólogo em Marte.

São Paulo, SP: Companhia das Letras, p.253.

Tustin, F. (1993). Autismeet protection. Paris: Seuil.

Willemart, P. (1995). Além da psicanálise: a literatura e as artes. São Paulo, SP: Nova Alexandria.

(1996). Psicanálise e pedagogia:

transmissão e formação. Revista USP, 31. - (1999). Proust, poèteet psychanalys-

te. Paris: L'Harmattan.

\section{NOTAS}

${ }^{1}$ Texto construído a partir da arguição pronunciada na defesa da livre-docência de Maria Cristina M. Kupfer e das respostas da candidata.

${ }^{2}$ Bonneuil pode ser lido "bon oeil", bom olho que manifesta o olhar posto nas crianças nessa casa.

3 "As medidas caracterizando o sono profundo correspondem a um atrator fractal com cinco variáveis independentes ... O emaranhado dos bilhões de neurônios que constituem nosso cérebro deixa-se representar ... por um sistema de equações relativamente simples, mas este sistema caracteriza-se, ele mesmo, por sua complexidade dinâmica intrínseca, pela instabilidade do comportamento que ele gera" (Prigogine, 1986, pp.15-6; a tradução é minha).

${ }^{4}$ Prigogine fala em estruturas dissipativas para explicar a passagem da instabilidade à estabilidade, e vice-versa.

${ }^{5}$ Freud já salientava o fenômeno da identificação para explicar a sectução dos leitores pelas históniasem Acriaçãoliteráriae oderaneio.

${ }^{6}$ Mas o alvo está explicado em Le mystère dans les lettres, de 1896: "As palavras, por si mesmas, exaltam-se em muitas facetas reconhecida a mais rara ou valiosa para o espírito, centro de suspense vibratório; que as percebe independentemente da seqüência ordinária, projetadas, em parede de gruta, tanto quanto dura sua mobilidade ou princípio, sendo o que não se diz do discurso: prontas todas, antes da extinção, a uma reciprocidade de fogos distante ou apresentada de viés como contingência" (Chiampi, 1991, p.131). 